\title{
Prognostic values of treatment modalities on head and neck mucosal melanomas in elderly patients: a population-based analysis
}

\author{
Enni Chen", Jiawei Wu", Zhiqiao Liu", Shanshan Yang, Jiali Wu, Puyun Ouyang, Fangyun Xie \\ Department of Radiation Oncology, Sun Yat-sen University Cancer Center, State Key Laboratory of Oncology in South China, Collaborative \\ Innovation Center for Cancer Medicine, Guangdong Key Laboratory of Nasopharyngeal Carcinoma Diagnosis and Therapy, Guangzhou, China \\ Contributions: (I) Conception and design: F Xie, P Ouyang, E Chen, J Wu; (II) Administrative support: F Xie; (III) Provision of study materials or \\ patients: S Yang; (IV) Collection and assembly of data: Z Liu; (V) Data analysis and interpretation: E Chen, J Wu; (VI) Manuscript writing: All \\ authors; (VII) Final approval of manuscript: All authors. \\ \#These authors contributed equally to this work. \\ Correspondence to: Fangyun Xie; Puyun Ouyang. Department of Radiation Oncology, Sun Yat-sen University Cancer Center, State Key Laboratory \\ of Oncology in South China, Collaborative Innovation Center for Cancer Medicine, Guangdong Key Laboratory of Nasopharyngeal Carcinoma \\ Diagnosis and Therapy, No. 651 Dongfeng East Road, Guangzhou 51000, China. Email: xiefy@sysucc.org.cn; ouyangpy@sysucc.org.cn.
}

Background: Head and neck mucosal melanoma (HNMM) is defined as a rare malignant tumor derived from melanocytes. There is no consensus regarding the treatment protocol for HNMM in elderly patients.

Methods: The National Cancer Institute's Surveillance, Epidemiology, and End Results database was used to identify elderly patients diagnosed with HNMM from 1975 to 2016 . The chi-squared test was used to compare patient characteristics. The reverse Kaplan-Meier method was used to estimate the median followup time. The Kaplan-Meier method and log-rank test were used to estimate and compare the overall survival (OS) and disease-specific survival (DSS) of the groups. Cox regression analysis was used to evaluate the risk factors for OS and DSS of HNMM.

Results: Our retrospective study included 828 elderly patients with HNMM, and the 5-year OS and DSS rates were $22.4 \%$ and $27.4 \%$, respectively. After adjusting for other variables in multivariate analysis, patients undergoing radiotherapy alone had worse OS [hazard ratio (HR) $=1.449,95 \%$ confidence interval (CI): 1.010-1.742, $\mathrm{P}=0.006]$ and DSS ( $\mathrm{HR}=1.656,95 \% \mathrm{CI}: 1.257-2.181, \mathrm{P}<0.001)$ than those undergoing surgery alone. No significant difference in OS (HR =0.892, 95\% CI: $0.753-1.056, \mathrm{P}=0.183$ ) or DSS (HR =0.917, 95\% CI: $0.764-1.101, \mathrm{P}=0.354$ ) was observed for patients undergoing surgery with or without radiotherapy. Our analysis of the subgroup of patients with complete clinical staging information demonstrated that the effects of surgery alone on OS ( $\mathrm{HR}=0.734,95 \% \mathrm{CI}$ : $0.562-0.958, \mathrm{P}=0.023$ ) were inferior to those of surgery with radiotherapy, but no significant difference was noted compared with radiotherapy alone.

Conclusions: The survival of elderly patients with HNMM is increased with the combination of surgery and radiotherapy compared with surgery alone and radiotherapy alone. In addition, the population-based analysis demonstrated that combination therapy exhibited an obviously increased usage rate from 1975 to 2016, representing a mainstream treatment modality.

Keywords: Mucosal melanoma (MM); head and neck cancer; survival analysis; radiotherapy; surgery

Submitted Aug 21, 2020. Accepted for publication Nov 27, 2020.

doi: $10.21037 /$ atm-20-6021

View this article at: http://dx.doi.org/10.21037/atm-20-6021 


\section{Introduction}

Melanomas refer to malignant tumors derived from melanocytes. Melanomas mostly originate from cutaneous tissues, while cases originating from mucosae are rare $(1,2)$. The incidence of mucosal melanoma (MM) increases with age, and the majority of patients are diagnosed at an age older than 60 years (3). The most common anatomic site for the occurrence of MM is the head and neck (4). Moreover, head and neck melanoma (HNMM) exhibits an aggressive course, with a poor prognosis in comparison to other melanoma subtypes $(4,5)$.

The combination of surgery and radiotherapy has been recommended for localized HNMM, while primary radiotherapy and/or systemic therapy are advocated in advanced cases (6). Given the scarcity of MM studies with relatively large sample sizes, a consensus about treatment protocols has not been achieved (7). Moreover, previous publications investigating the effects of treatment modalities on HNMM in elderly patients are lacking. Herein, using the database of the National Cancer Institute's Surveillance, Epidemiology, and End Results (SEER), we investigated the role of different treatment modalities on the survival outcomes of elderly patients with HNMM. We present the following article in accordance with the STROBE reporting checklist (available at http://dx.doi.org/10.21037/atm-20-6021).

\section{Methods}

The study conformed to the provisions of the Declaration of Helsinki (as revised in 2013).

\section{Data source and population}

Our study retrospectively reviewed patients using the SEER database, which is an authoritative source for cancer statistics in the USA. Due to the deidentified nature of data in SEER, the study was exempt from ethics committee approval. To identify HNMM cases, we used the International Classification of Disease for Oncology third edition (ICDO-3) topography codes for the following head and neck subsites: the nasal cavity (C30.0), paranasal sinuses (C31.0-C31.9) and other sites (lip (C00.3-C00.9), base of tongue (C01.9), other and unspecific parts of tongue (C01.0-C01.9), gums (C03.0-C03.9), floor of mouth (C04.0-C04.9), plate (C05.0-C05.9), other and unspecified parts of the mouth (C06.0-C069), tonsil (C09.0-C09.9), oropharynx (C10.0-C10.9), nasopharynx (C11.0-C11.9), pyriform sinus (C12.9), hypopharynx (C13.0-13.9), other and ill-defined sits in lip, oral cavity and pharynx (C14.0-C14.8), and larynx (C32.0-C32.9) as well as histological codes for mucosal melanoma (8720-8790). The study population included patients who were diagnosed with HNMM and treated by surgery and/or radiotherapy in the SEER database from 1975 to 2016. Patients less than 65 years old and those with MM metastasis and lacking local definitive therapies were excluded (Figure 1). All patients were characterized by sex, gender, race, age at diagnosis, marital status, primary site, TN stage, tumor size, years of diagnosis and treatment modalities. The grouping of age at diagnosis and tumor size was according to patients' median age at diagnosis in the overall cohort and the criteria of another similar study (4), respectively. Survival outcome was also obtained from SEER and coded from the index diagnosis to date of death or last known followup. Moreover, OS and DSS was obtained based on SEER cause-specific classification.

\section{Statistical analysis}

To compare patient characteristics, the chi-squared test was used. OS and DSS were estimated using the Kaplan-Meier method and compared using log-rank tests. Median followup was estimated using the reverse Kaplan-Meier method. Cox regression analysis was used to estimate hazard ratio (HR) and 95\% confidence interval (CI) to identify the risk factors for OS and DSS of HNMM. Statistical analyses were conducted using Stata version 14.1 (StataCorp LP, College Station, Texas, USA). A two-sided $\mathrm{P}$ value less than 0.05 was considered statistically significant.

\section{Results}

A total of 1,504 elderly patients were diagnosed with HNMM between 1975 and 2016, and 828 of them were available for our study, with a 69-month median follow-up time, 5-year overall survival (OS) of $22.4 \%$ and disease-specific survival (DSS) of $27.4 \%$ (Figure S1). In total, 381 patients were included in the surgery alone group, 82 in the radiotherapy alone group and 365 in the surgery with radiotherapy group. Their characteristics are shown in Table 1. Median age $(\mathrm{P}<0.001)$, marital status $(\mathrm{P}=0.001)$, primary site of tumor $(\mathrm{P}<0.001)$, $\mathrm{T}$ classification $(\mathrm{P}=0.001), \mathrm{N}$ classification $(\mathrm{P}=0.007)$, tumor size $(\mathrm{P}<0.001)$ and years of diagnosis $(\mathrm{P}=0.001)$ significantly differed among the three groups. In general, the proportion of elderly HNMM patients who 


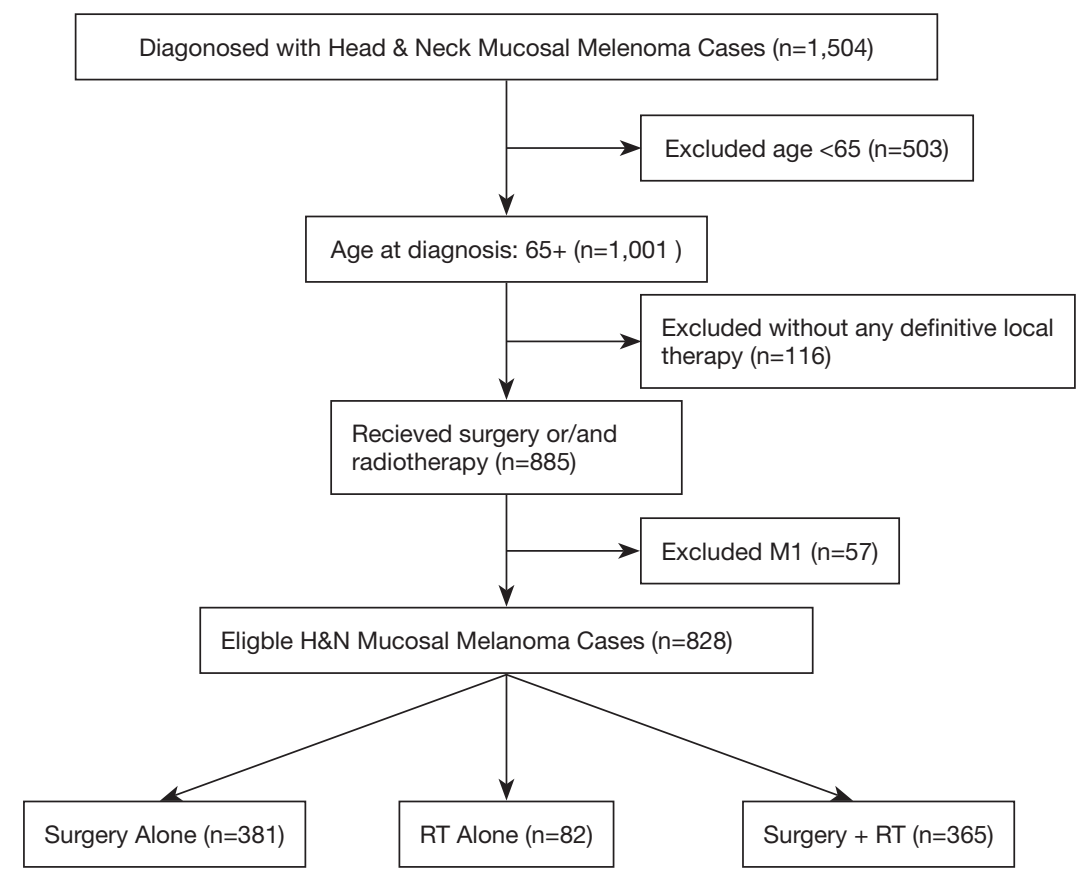

Figure 1 Cohort composition.

underwent combined surgery and radiotherapy increased obviously and exceeded that of patients who underwent surgery alone recently, whereas use of radiotherapy alone remained at the lowest level over this period (Figure 2).

Regarding definitive local treatments, surgery with radiotherapy, radiotherapy alone and surgery alone groups were associated with a 5 -year DSS of $31.1 \%$, $10.9 \%$ and $27.1 \%$, respectively, and OS values of $27.2 \%$, $10.9 \%$ and $20.6 \%$, respectively (Figure $3 A, B$ ). Univariate analysis demonstrated that compared with the other two treatment modalities, radiotherapy alone accounted for the poorer OS and DSS. Multivariate analysis reported the same outcome, namely, that radiotherapy alone was associated with a relatively poor OS (HR $=1.449,95 \% \mathrm{CI}$ : $1.010-1.742, \mathrm{P}=0.006)$ and DSS $(\mathrm{HR}=1.656,95 \% \mathrm{CI}$ : $1.257-2.181, \mathrm{P}<0.001)$. Moreover, no significant difference in OS (HR $=0.892,95 \% \mathrm{CI}: 0.753-1.056, \mathrm{P}=0.183)$ or DSS (HR $=0.917,95 \%$ CI: 0.764-1.101, $\mathrm{P}=0.354$ ) between the surgery alone and surgery with radiotherapy group was observed in the multivariate analysis. Regarding other variables, age over 77 , melanoma of the paranasal sinuses, tumor size greater than $4 \mathrm{~cm}$ and $\mathrm{N} 1$ stage were considered independent predictors of worse OS and DSS in the multivariate analysis. Moreover, T4a represented an independent predictor for worse OS, whereas better OS was observed in single patients (Tables 2,3).

We conducted a subgroup analysis for 372 patients with complete $\mathrm{T}$ and $\mathrm{N}$ staging who were diagnosed in 2004 or later because cases diagnosed before 2004 lack $\mathrm{T}$ and $\mathrm{N}$ staging data in SEER. The 5-year DSS of the surgery and radiotherapy, radiotherapy alone and surgery alone groups was $29.1 \%, 14.5 \%$ and $23.6 \%$, respectively, while the corresponding 5 -year OS was $26.2 \%, 14.0 \%$ and $17.5 \%$, respectively (Figure $3 C, D$ ). Unlike the results in Table 2 and Table 3, a significant increase in 5-year OS $(\mathrm{HR}=0.734,95 \%$ CI: $0.562-0.958, \mathrm{P}=0.023)$ in the surgery with radiotherapy group was observed compared with that in the surgery alone group, but no significant improvement in DSS (HR $=0.767,95 \%$ CI: $0.578-1.017, \mathrm{P}=0.066$ ) was noted (Tables 4,5 ). In addition, patients in the surgery alone and radiotherapy alone groups exhibited no significant difference in OS (HR $=1.126,95 \%$ CI: 0.715-1.773, $\mathrm{P}=0.608)$ or DSS (HR $=1.185,95 \%$ CI: $0.736-1.908$, $\mathrm{P}=0.484)$. Moreover, independent predictors in this subgroup included melanoma of the paranasal sinuses, tumor size greater than $4 \mathrm{~cm}$ and T4a stage, which were associated with a worse OS and DSS. T4b and age over 77 exclusively accounted for the worse OS. 
Table 1 Characteristics of elderly patients with head and neck melanoma, stratified by treatment modalities

\begin{tabular}{|c|c|c|c|c|}
\hline Characteristics & Surgery alone $(n=381)$ & RT alone $(n=82)$ & Surgery and RT $(n=365)$ & $P$ value \\
\hline$<77$ & $149(39.1 \%)$ & $28(34.1 \%)$ & $205(56.2 \%)$ & \\
\hline$\geq 77$ & 232 (60.9\%) & $54(65.9 \%)$ & $160(43.8 \%)$ & \\
\hline Gender & & & & 0.200 \\
\hline Female & 205 (53.8\%) & $53(64.6 \%)$ & 202 (55.3\%) & \\
\hline Race & & & & 0.263 \\
\hline White & $332(87.1 \%)$ & $65(79.3 \%)$ & 322 (88.2\%) & \\
\hline Black & 19 (5.0\%) & $7(8.5 \%)$ & $13(3.6 \%)$ & \\
\hline Married & $176(46.2 \%)$ & $37(45.1 \%)$ & 217 (59.5\%) & \\
\hline Single & 29 (7.6\%) & $6(7.3 \%)$ & $16(4.4 \%)$ & \\
\hline Widowed & $23(6.0 \%)$ & $6(7.3 \%)$ & $31(8.5 \%)$ & \\
\hline Divorced/separated & $123(32.3 \%)$ & 27 (32.9\%) & $92(25.2 \%)$ & \\
\hline Unknown & $30(7.9 \%)$ & $6(7.3 \%)$ & $9(2.5 \%)$ & \\
\hline Primary site & & & & $<0.001^{*}$ \\
\hline Nasal cavity & $197(51.7 \%)$ & $36(43.9 \%)$ & 217 (59.5\%) & \\
\hline Paranasal sinuses & $61(16.0 \%)$ & $28(34.1 \%)$ & $100(27.4 \%)$ & \\
\hline Unknown & $225(59.1 \%)$ & $47(57.3 \%)$ & $171(46.8 \%)$ & \\
\hline $\mathrm{N}$ stage & & & & $0.007^{*}$ \\
\hline No & $182(47.8 \%)$ & $30(36.6 \%)$ & $201(55.1 \%)$ & \\
\hline $\mathrm{N} 1$ & $22(5.8 \%)$ & $3(3.7 \%)$ & $24(6.6 \%)$ & \\
\hline Unknown & 177 (46.5\%) & 49 (59.8\%) & $140(38.4 \%)$ & \\
\hline Tumor size (cm) & & & & $<0.001^{*}$ \\
\hline$\leq 2$ & $68(17.8 \%)$ & $2(2.4 \%)$ & 60 (16.4\%) & \\
\hline $2-4$ & 49 (12.9\%) & $11(13.4 \%)$ & $76(20.8 \%)$ & \\
\hline$>4$ & $35(9.2 \%)$ & $14(17.1 \%)$ & 37 (10.1\%) & \\
\hline Unknown & $229(60.1 \%)$ & 55 (67.1\%) & 192 (52.6\%) & \\
\hline
\end{tabular}

Table 1 (continued) 
Table 1 (continued)

\begin{tabular}{|c|c|c|c|c|}
\hline Characteristics & Surgery alone $(n=381)$ & RT alone $(n=82)$ & Surgery and RT $(n=365)$ & $P$ value \\
\hline $1975-1981$ & $20(5.2 \%)$ & $3(3.7 \%)$ & $4(1.1 \%)$ & \\
\hline $1982-1988$ & $22(5.8 \%)$ & $5(6.1 \%)$ & $17(4.7 \%)$ & \\
\hline 1989-1995 & $33(8.7 \%)$ & $15(18.3 \%)$ & $39(10.7 \%)$ & \\
\hline 2003-2009 & 127 (33.3\%) & $16(19.5 \%)$ & 110 (30.1\%) & \\
\hline 2010-2016 & $102(26.8 \%)$ & $23(28.0 \%)$ & $134(36.7 \%)$ & \\
\hline
\end{tabular}

*, two-sided $\mathrm{P}$ value $<0.05$. $\mathrm{RT}$, radiotherapy.

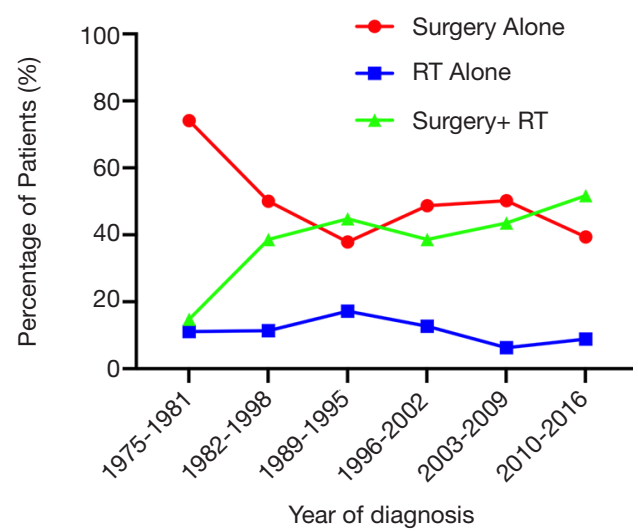

Figure 2 Rates of use of surgery alone, radiotherapy (RT) alone and surgery with radiotherapy from 1975 to 2016 for head and neck melanoma in elderly patients.

\section{Discussion}

To our knowledge, there is currently no published literature exclusively focusing on HNMM in elderly patients. Thus, we sought to evaluate the impact of treatment modalities on the prognosis of those patients. Although cases less than 65 years of age were excluded, the median age of 77 in both the overall cohort and subgroup in our study was close to that in other studies that had a much wider cohort age range $(8,9)$. Thus, our cohort composition plausibly explained the 5 -year OS and DSS rates of $22.4 \%$ and $27.4 \%$, respectively, which were poorer than those in others, ranging from $25.2 \%$ to $35.1 \%$ and $28.7 \%$ to $43.6 \%$, respectively (4,9-11).

The use of radiotherapy as a primary therapy remains controversial $(12,13)$, whereas surgery is considered the main treatment option for most HNMM. However, prospective, randomized trials supporting this approach are lacking (5). In our study, the worse survival outcome was associated with radiotherapy alone than with the other two local treatment modalities in multivariate analysis of the overall cohort, which was consistent with previous literature on HNMM patients of all ages $(9,14,15)$. This result may be attributed to the greater influence of the patient's physical status and stage of HNMM instead of function of treatment itself. Patients who cannot be treated with or tolerant of surgery are more likely to have more advanced, aggressive and less completely resected MM, and these features are typically associated with a poor prognosis. However, it is notable that there was an inconsistent result in the subgroup analysis, revealing no significant difference in the OS and DSS of patients undergoing radiotherapy alone and surgery alone after eliminating the interference by cases with an inexplicit TN stage on the assessment of prognostic value of treatment modalities. We believe that it is possible that the effects of exclusively using surgery or radiotherapy on survival were similar for elderly patients who usually underwent a more aggressive course with a relatively poor prognosis.

Radiotherapy can be an adjuvant to surgery in the case of an anatomic site restricting the completion of en bloc negative margin resection without excessive morbidity or access to tumors $(12,15)$. In addition, multiple positive nodes and extracapsular tumor spread warrant adjuvant radiotherapy (15). Despite clinical and basic scientific evidence demonstrating the radiation-resistant nature of HNMM $(11,16)$, an improvement of outcomes with respect to local and locoregional control was achieved by combining surgery and radiotherapy compared with surgery alone, but no survival advantage had been observed in multiple studies (17-19). Interestingly, the present 
A

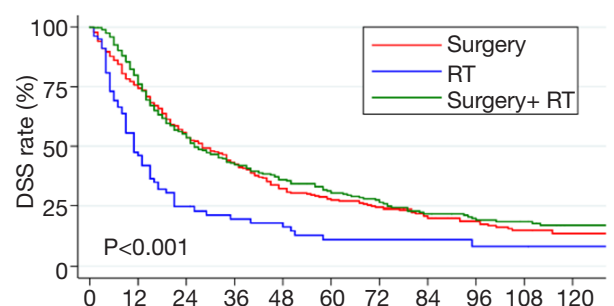
Number at risk

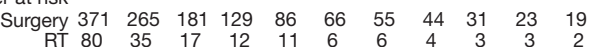
Surgery + RT $\begin{array}{lllllllllll}363 & 279 & 170 & 116 & 87 & 70 & 52 & 38 & 30 & 26 & 19\end{array}$

C

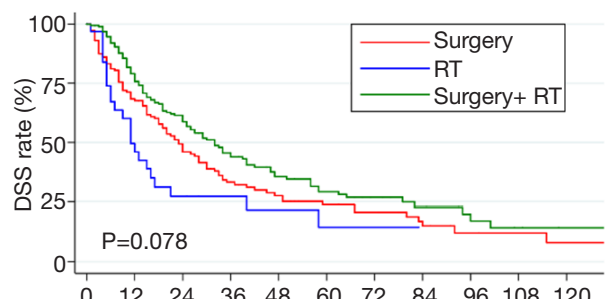
Number at risk

$\begin{array}{rlllllllllll}\text { Surgery } & 145 & 95 & 58 & 33 & 23 & 17 & 14 & 9 & 4 & 3 & 1 \\ \text { RT } & 32 & 14 & 7 & 5 & 4 & 2 & 2 & 0 & 0 & 0 & 0\end{array}$
B

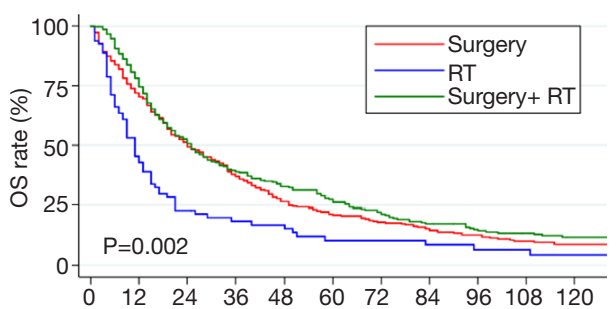

Number at risk

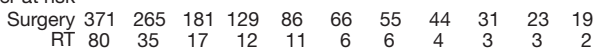
Surgery + RT $\begin{array}{lllllllllll}363 & 279 & 170 & 116 & 87 & 70 & 52 & 38 & 30 & 26 & 19\end{array}$

$\mathrm{D}$

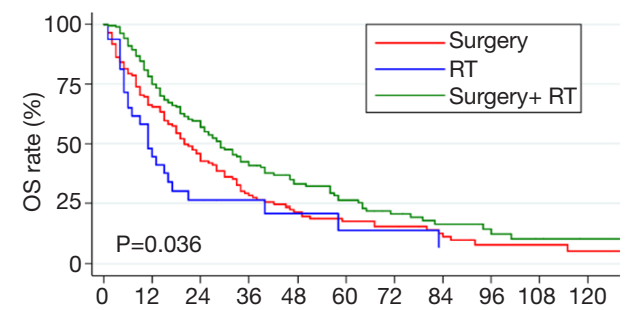

Number at risk

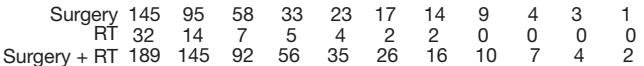

Figure 3 Disease-specific survival (DSS) and overall survival (OS) in the overall cohort (A and B) and subgroup (C and D) of elderly patients with head and neck mucosal melanomas, stratified by surgery alone, radiotherapy (RT) alone and surgery with radiotherapy.

Table 2 Univariate and multivariate analysis of overall survival in the overall cohort of elderly patients with head and neck melanoma

\begin{tabular}{|c|c|c|c|c|}
\hline Variable & \multicolumn{2}{|c|}{ Univariate analysis } & \multicolumn{2}{|c|}{ Multivariate analysis } \\
\hline \multicolumn{5}{|l|}{ Age (median) } \\
\hline$<77$ & 1.000 (reference) & & 1.000 (reference) & \\
\hline$\geq 77$ & $1.430(1.229-1.664)$ & $<0.001^{*}$ & $1.398(1.189-1.645)$ & $<0.001^{*}$ \\
\hline Male & 1.000 (reference) & & & \\
\hline Female & $0.942(0.811-1.094)$ & 0.435 & & \\
\hline \multicolumn{5}{|l|}{ Race } \\
\hline White & 1.000 (reference) & & 1.000 (reference) & \\
\hline \multicolumn{5}{|l|}{ Marital status } \\
\hline Married & 1.000 (reference) & & 1.000 (reference) & \\
\hline Single & $0.821(0.590-1.144)$ & 0.244 & $0.711(0.508-0.995)$ & $0.047^{\star}$ \\
\hline Widowed & $1.108(0.826-1.487)$ & 0.494 & $1.122(0.830-1.515)$ & 0.455 \\
\hline Divorced/separated & $1.278(1.079-1.513)$ & $0.004^{*}$ & $1.127(0.942-1.348)$ & 0.192 \\
\hline Unknown & $1.196(0.841-1.701)$ & 0.320 & $1.191(0.833-1.703)$ & 0.339 \\
\hline
\end{tabular}

Table 2 (continued) 
Table 2 (continued)

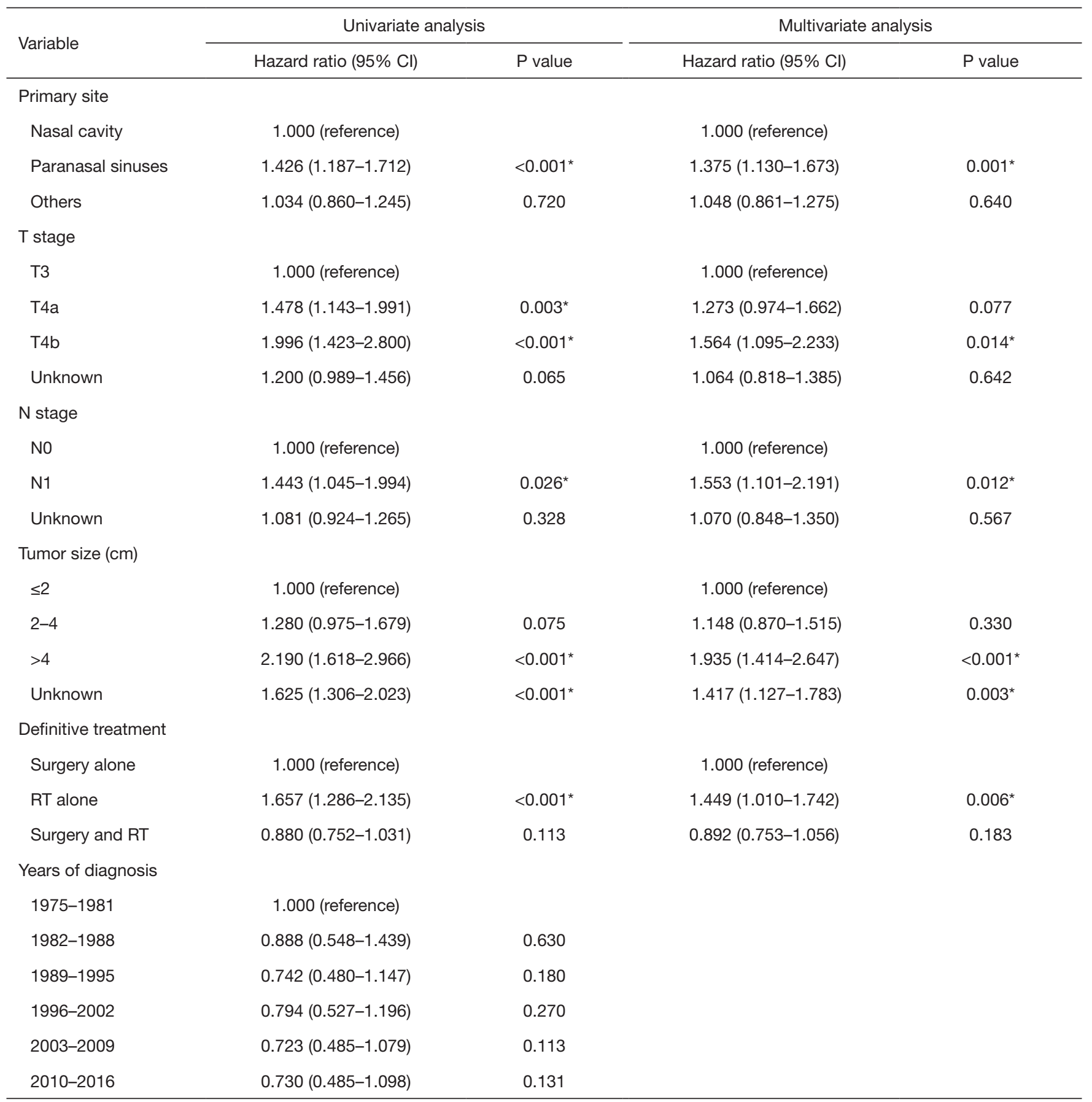

*, two-sided $\mathrm{P}$ value $<0.05$. Cl, confidence interval; $\mathrm{RT}$, radiotherapy. 
Table 3 Univariate and multivariate analysis of disease-specific survival in the overall cohort of elderly patients with head and neck melanoma

\begin{tabular}{|c|c|c|c|c|}
\hline Variable & \multicolumn{2}{|c|}{ Univariate analysis } & \multicolumn{2}{|c|}{ Multivariate analysis } \\
\hline \multicolumn{5}{|l|}{ Age (median) } \\
\hline$<77$ & 1.000 (reference) & & 1.000 (reference) & \\
\hline$\geq 77$ & $1.243(1.057-1.462)$ & $0.009^{*}$ & $1.243(1.044-1.480)$ & $0.014^{*}$ \\
\hline Male & 1.000 (reference) & & & \\
\hline Female & $0.889(0.756-1.045)$ & 0.155 & & \\
\hline \multicolumn{5}{|l|}{ Race } \\
\hline White & 1.000 (reference) & & & \\
\hline \multicolumn{5}{|l|}{ Marital status } \\
\hline Married & 1.000 (reference) & & 1.000 (reference) & \\
\hline Single & $0.816(0.569-1.168)$ & 0.266 & $0.746(0.518-1.074)$ & 0.115 \\
\hline Widowed & $1.206(0.889-1.637)$ & 0.228 & $1.210(0.885-1.654)$ & 0.231 \\
\hline Divorced/separated & $1.236(1.028-1.486)$ & $0.024^{*}$ & $1.137(0.937-1.381)$ & 0.194 \\
\hline Unknown & $1.265(0.874-1.832)$ & 0.212 & $1.223(0.840-1.780)$ & 0.294 \\
\hline \multicolumn{5}{|l|}{ Primary site } \\
\hline Nasal cavity & 1.000 (reference) & & 1.000 (reference) & \\
\hline $\mathrm{T} 4 \mathrm{~b}$ & $1.873(1.293-2.714)$ & $0.001^{*}$ & $1.423(0.964-2.098)$ & 0.076 \\
\hline Unknown & $1.183(0.962-1.454)$ & 0.111 & $1.122(0.849-1.483)$ & 0.417 \\
\hline \multicolumn{5}{|l|}{$\mathrm{N}$ stage } \\
\hline No & 1.000 (reference) & & 1.000 (reference) & \\
\hline $\mathrm{N} 1$ & $1.659(1.198-2.298)$ & $0.002^{*}$ & $1.734(1.224-2.457)$ & $0.002^{*}$ \\
\hline Unknown & $1.036(0.875-1.228)$ & 0.680 & $0.992(0.773-1.273)$ & 0.950 \\
\hline \multicolumn{5}{|l|}{ Tumor size (cm) } \\
\hline$\leq 2$ & 1.000 (reference) & & 1.000 (reference) & \\
\hline $2-4$ & $1.352(1.004-1.820)$ & $0.047^{\star}$ & $1.236(0.913-1.675)$ & 0.171 \\
\hline$>4$ & $2.376(1.715-3.291)$ & $<0.001^{*}$ & $2.025(1.445-2.839)$ & $<0.001^{*}$ \\
\hline Unknown & 1.705 (1.339-2.172) & $<0.001^{*}$ & $1.517(1.179-1.953)$ & $0.001^{*}$ \\
\hline
\end{tabular}

Table 3 (continued) 
Table 3 (continued)

\begin{tabular}{|c|c|c|c|c|}
\hline Variable & \multicolumn{2}{|c|}{ Univariate analysis } & \multicolumn{2}{|c|}{ Multivariate analysis } \\
\hline \multicolumn{5}{|c|}{ Definitive treatment } \\
\hline Surgery alone & 1.000 (reference) & & 1.000 (reference) & \\
\hline RT alone & $1.873(1.434-2.447)$ & $<0.001^{*}$ & $1.656(1.257-2.181)$ & $<0.001^{*}$ \\
\hline \multicolumn{5}{|l|}{ Years of diagnosis } \\
\hline $1975-1981$ & 1.000 (reference) & & & \\
\hline $1982-1988$ & $0.801(0.479-1.339)$ & 0.397 & & \\
\hline 1989-1995 & $0.672(0.424-1.065)$ & 0.090 & & \\
\hline 2010-2016 & $0.683(0.446-1.045)$ & 0.079 & & \\
\hline
\end{tabular}

${ }^{*}$, two-sided $\mathrm{P}$ value $<0.05$. Cl, confidence interval; $\mathrm{RT}$, radiotherapy.

Table 4 Univariate and multivariate analysis of overall survival in the subgroup of elderly patients with head and neck melanoma

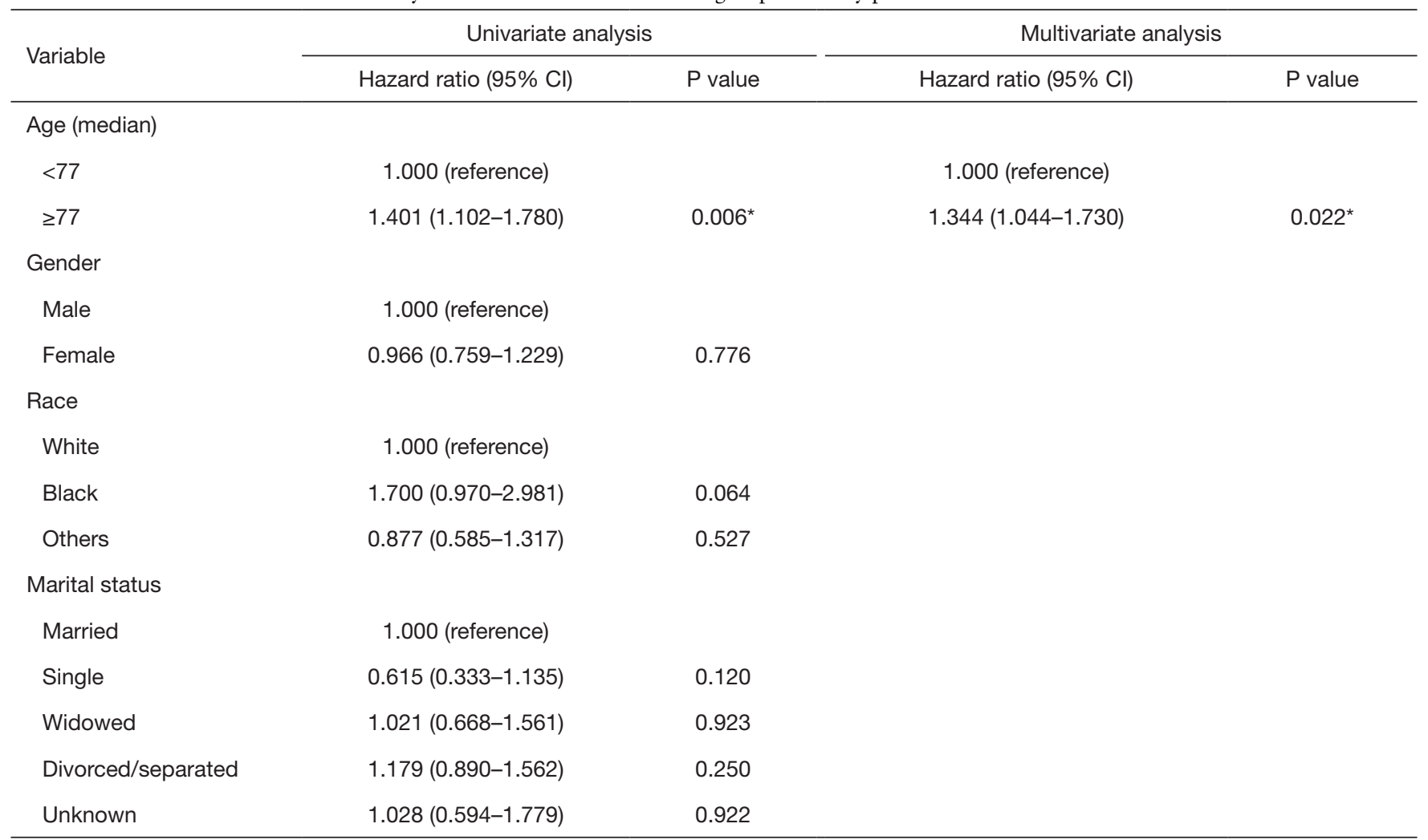

Table 4 (continued) 
Table 4 (continued)

\begin{tabular}{|c|c|c|c|c|}
\hline Variable & \multicolumn{2}{|c|}{ Univariate analysis } & \multicolumn{2}{|c|}{ Multivariate analysis } \\
\hline \multicolumn{5}{|l|}{ Primary site } \\
\hline Nasal cavity & 1.000 (reference) & & 1.000 (reference) & \\
\hline Paranasal sinuses & $1.729(1.313-2.276)$ & $<0.001^{*}$ & $1.525(1.145-2.031)$ & $0.004^{*}$ \\
\hline \multicolumn{5}{|l|}{ T stage } \\
\hline T3 & 1.000 (reference) & & 1.000 (reference) & \\
\hline $\mathrm{T} 4 \mathrm{a}$ & $1.518(1.164-1.982)$ & $0.002^{*}$ & $1.446(1.092-1.914)$ & $0.010^{*}$ \\
\hline $\mathrm{T} 4 \mathrm{~b}$ & $2.001(1.412-2.836)$ & $<0.001^{*}$ & $1.654(1.120-2.442)$ & $0.011^{*}$ \\
\hline N1 & $1.511(1.013-2.255)$ & $0.043^{*}$ & $1.302(0.839-2.021)$ & 0.239 \\
\hline \multicolumn{5}{|l|}{ Tumor size (cm) } \\
\hline$\leq 2$ & 1.000 (reference) & & 1.000 (reference) & \\
\hline $2-4$ & $1.155(0.773-1.728)$ & 0.482 & $0.969(0.640-1.468)$ & 0.883 \\
\hline$>4$ & $2.582(1.717-3.882)$ & $<0.001^{*}$ & $2.167(1.402-3.348)$ & $<0.001^{*}$ \\
\hline Unknown & $1.545(1.120-2.131)$ & $0.008^{*}$ & $1.316(0.940-1.843)$ & 0.110 \\
\hline \multicolumn{5}{|l|}{ Definitive treatment } \\
\hline Surgery alone & 1.000 (reference) & & 1.000 (reference) & \\
\hline
\end{tabular}

*, two-sided $\mathrm{P}$ value $<0.05$. $\mathrm{Cl}$, confidence interval; $\mathrm{RT}$, radiotherapy.

Table 5 Univariate and multivariate analysis of disease-specific survival in the subgroup of elderly patients with head and neck melanoma

\begin{tabular}{|c|c|c|c|c|}
\hline Variable & \multicolumn{2}{|c|}{ Univariate analysis } & \multicolumn{2}{|c|}{ Multivariate analysis } \\
\hline \multicolumn{5}{|c|}{ Age (median) } \\
\hline$<77$ & 1.000 (reference) & & 1.000 (reference) & \\
\hline$\geq 77$ & $1.298(1.008-1.672)$ & $0.043^{*}$ & $1.278(0.978-1.670)$ & 0.073 \\
\hline Male & 1.000 (reference) & & & \\
\hline Female & $0.933(0.723-1.204)$ & 0.594 & & \\
\hline
\end{tabular}

Table 5 (continued) 
Table 5 (continued)

\begin{tabular}{|c|c|c|c|c|}
\hline Variable & \multicolumn{2}{|c|}{ Univariate analysis } & \multicolumn{2}{|c|}{ Multivariate analysis } \\
\hline \multicolumn{5}{|l|}{ Race } \\
\hline White & 1.000 (reference) & & & \\
\hline Black & $1.713(0.965-3.105)$ & 0.066 & & \\
\hline \multicolumn{5}{|l|}{ Marital status } \\
\hline Married & 1.000 (reference) & & & \\
\hline Single & $0.501(0.246-1.024)$ & 0.058 & & \\
\hline Widowed & $1.032(0.663-1.608)$ & 0.889 & & \\
\hline \multicolumn{5}{|l|}{ Primary site } \\
\hline Nasal cavity & 1.000 (reference) & & 1.000 (reference) & \\
\hline Paranasal sinuses & $1.715(1.278-2.300)$ & $<0.001^{*}$ & $1.497(1.102-2.034)$ & $0.010^{*}$ \\
\hline Others & $1.344(0.973-1.857)$ & 0.073 & $1.360(0.951-1.944)$ & 0.092 \\
\hline \multicolumn{5}{|l|}{ T stage } \\
\hline T3 & 1.000 (reference) & & 1.000 (reference) & \\
\hline $\mathrm{T} 4 \mathrm{a}$ & $1.624(1.229-2.145)$ & $0.001^{*}$ & $1.537(1.146-2.062)$ & $0.004^{*}$ \\
\hline $\mathrm{T} 4 \mathrm{~b}$ & $1.912(1.307-2.798)$ & $0.001^{*}$ & $1.522(0.999-2.320)$ & 0.051 \\
\hline \multicolumn{5}{|l|}{$\mathrm{N}$ stage } \\
\hline $2-4$ & $1.183(0.766-1.829)$ & 0.448 & $0.984(0.629-1.541)$ & 0.945 \\
\hline$>4$ & 2.864 (1.864-4.399) & $<0.001^{*}$ & $2.411(1.525-3.812)$ & $<0.001^{*}$ \\
\hline Unknown & $1.638(1.158-2.316)$ & $0.005^{\star}$ & 1.427 (0.994-2.049) & 0.054 \\
\hline \multicolumn{5}{|l|}{ Definitive treatment } \\
\hline Surgery alone & 1.000 (reference) & & 1.000 (reference) & \\
\hline RT alone & $1.457(0.925-2.293)$ & 0.104 & $1.185(0.736-1.908)$ & 0.484 \\
\hline Surgery and RT & $0.751(0.576-0.979)$ & $0.034^{*}$ & $0.767(0.578-1.017)$ & 0.066 \\
\hline \multicolumn{5}{|l|}{ Years of diagnosis } \\
\hline 2003-2009 & 1.000 (reference) & & & \\
\hline 2010-2016 & $0.907(0.698-1.179)$ & 0.465 & & \\
\hline
\end{tabular}

*, two-sided $\mathrm{P}$ value $<0.05$. Cl, confidence interval; $\mathrm{RT}$, radiotherapy. 
subgroup analysis results demonstrated that compared with surgery alone, the use of a combination of surgery and radiotherapy obviously decreased the risk of a poorer OS but had no effect on a significant improvement in DSS for elderly patients with HNMM. Regardless, we still believe that radiotherapy incorporated into the multimodality treatment paradigm of HNMM is beneficial to elderly patients in terms of survival

There were limitations in this analysis. Given the retrospective nature of our study, the association of survival outcome with treatment modalities may be investigated, but their causation may not be deduced. Moreover, missing data and patients lost to follow-up can result in selection and information bias. The data for local and locoregional control effects, recurrence and other factors were not included in the SEER database, so a more complete assessment on the effects of different treatment modalities on HNMM in elderly patients could not be conducted.

\section{Conclusions}

With the advanced development of radiotherapy techniques, the rate of usage as a component of multimodalities treatment paradigms has generally experienced remarkable growth. This combined therapy has become the mainstream for elderly patients with HNMM. In this study, regarding survival outcomes of elderly patients, the combination of surgery and radiotherapy yielded a significant improvement and was superior to surgery alone and radiotherapy alone. However, survival of this patient population remained low regardless of the type of treatment modality.

\section{Acknowledgments}

We thank the contribution of the SEER database and the 18 registries supplying cancer research information.

Funding: This work was supported by the Sun Yat-sen University Clinical Research 5010 Program (2015020), the National Natural Science Foundation of China (81672665), the Sci-Tech Project Foundation of Guangdong Province (2016A020215087), and the Natural Science Foundation of Guangdong Province (2019A1515010300).

\section{Footnote}

Reporting Checklist: The authors have completed the STROBE reporting checklist. Available at http://dx.doi. org/10.21037/atm-20-6021
Conflicts of Interest: All authors have completed the ICMJE uniform disclosure form (available at http://dx.doi. org/10.21037/atm-20-6021). The authors have no conflicts of interest to declare.

Ethical Statement: The authors are accountable for all aspects of the work in ensuring that questions related to the accuracy or integrity of any part of the work are appropriately investigated and resolved. The study conformed to the provisions of the Declaration of Helsinki (as revised in 2013).

Open Access Statement: This is an Open Access article distributed in accordance with the Creative Commons Attribution-NonCommercial-NoDerivs 4.0 International License (CC BY-NC-ND 4.0), which permits the noncommercial replication and distribution of the article with the strict proviso that no changes or edits are made and the original work is properly cited (including links to both the formal publication through the relevant DOI and the license). See: https://creativecommons.org/licenses/by-nc-nd/4.0/.

\section{References}

1. Postow MA, Hamid O, Carvajal RD. Mucosal melanoma: pathogenesis, clinical behavior, and management. Curr Oncol Rep 2012;14:441-8.

2. Yde SS, Sjoegren P, Heje M, et al. Mucosal Melanoma: a Literature Review. Curr Oncol Rep 2018;20:28.

3. Mihajlovic M, Vlajkovic S, Jovanovic P, et al. Primary mucosal melanomas: a comprehensive review. Int $\mathrm{J}$ Clin Exp Pathol 2012;5:739-53.

4. Jethanamest D, Vila PM, Sikora AG, et al. Predictors of survival in mucosal melanoma of the head and neck. Ann Surg Oncol 2011;18:2748-56.

5. Ascierto PA, Accorona R, Botti G, et al. Mucosal melanoma of the head and neck. Crit Rev Oncol Hematol 2017;112:136-52.

6. National Comprehensive Cancer Network. Mucosal Melanoma (Version 2.2020). 2020; Available online: http:// www.nccn.org/professionals/physician_gls/pdf/head-andneck.pdf

7. Lazarev S, Gupta V, Hu K, et al. Mucosal melanoma of the head and neck: a systematic review of the literature. Int J Radiat Oncol Biol Phys 2014;90:1108-18.

8. Al-Haseni A, Vrable A, Qureshi MM, et al. Survival outcomes of mucosal melanoma in the USA. Future Oncol 2019;15:3977-86. 
9. Schmidt MQ, David J, Yoshida EJ, et al. Predictors of survival in head and neck mucosal melanoma. Oral Oncology 2017;73:36-42.

10. Bachar G, Loh KS, O'Sullivan B, et al. Mucosal melanomas of the head and neck: experience of the Princess Margaret Hospital. Head Neck 2008;30:1325-31.

11. Patel SG, Prasad ML, Escrig M, et al. Primary mucosal malignant melanoma of the head and neck. Head Neck 2002;24:247-57.

12. Çomoğlu Ş, Polat B, Celik M, et al. Prognostic factors in head and neck mucosal malignant melanoma. Auris Nasus Larynx 2018;45:135-42.

13. Lawaetz M, Birch-Johansen F, Friis S, et al. Primary mucosal melanoma of the head and neck in Denmark, 1982-2012: Demographic and clinical aspects. A retrospective DAHANCA study. Acta Oncol 2016;55:1001-8.

14. Gal TJ, Silver N, Huang B. Demographics and treatment

Cite this article as: Chen E, Wu J, Liu Z, Yang S, Wu J, Ouyang P, Xie F. Prognostic values of treatment modalities on head and neck mucosal melanomas in elderly patients: a population-based analysis. Ann Transl Med 2021;9(5):391. doi: 10.21037/atm-20-6021 trends in sinonasal mucosal melanoma. Laryngoscope 2011;121:2026-33.

15. Plavc G, But-Hadžić J, Aničin A, et al. Mucosal melanoma of the head and neck: a population-based study from Slovenia, 1985-2013. Radiat Oncol 2016;11:137.

16. Medina JE, Ferlito A, Pellitteri PK, et al. Current management of mucosal melanoma of the head and neck. J Surg Oncol 2003;83:116-22.

17. Frakes JM, Strom TJ, Naghavi AO, et al. Outcomes of mucosal melanoma of the head and neck. J Med Imaging Radiat Oncol 2016;60:268-73.

18. Saigal K, Weed DT, Reis IM, et al. Mucosal melanomas of the head and neck: the role of postoperative radiation therapy. ISRN Oncol 2012;2012:785131.

19. Wagner M, Morris CG, Werning JW, et al. Mucosal melanoma of the head and neck. Am J Clin Oncol 2008;31:43-8. 


\section{Supplementary}

A

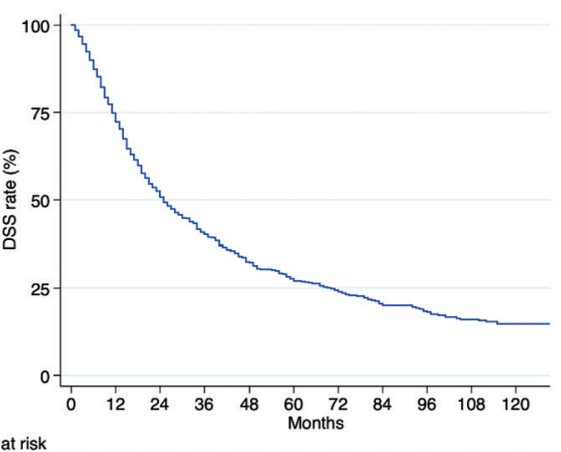

Number at risk $\begin{array}{lllllllllll}814 & 579 & 368 & 257 & 184 & 142 & 113 & 86 & 64 & 52 & 40\end{array}$

C

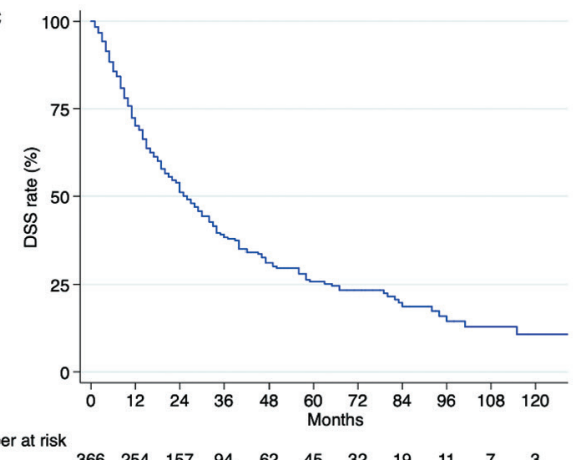

B

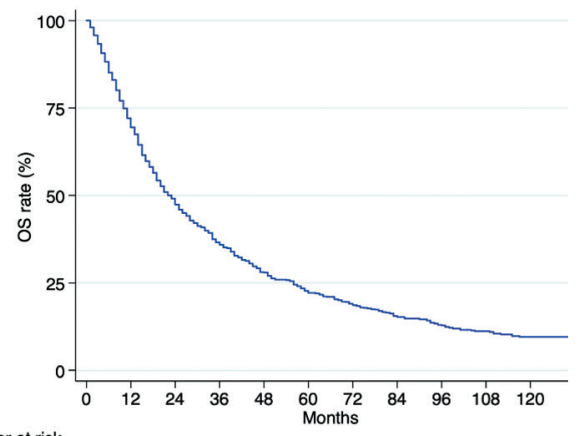

Number at risk

$\begin{array}{lllllllllll}814 & 579 & 368 & 257 & 184 & 142 & 113 & 86 & 64 & 52 & 40\end{array}$

D

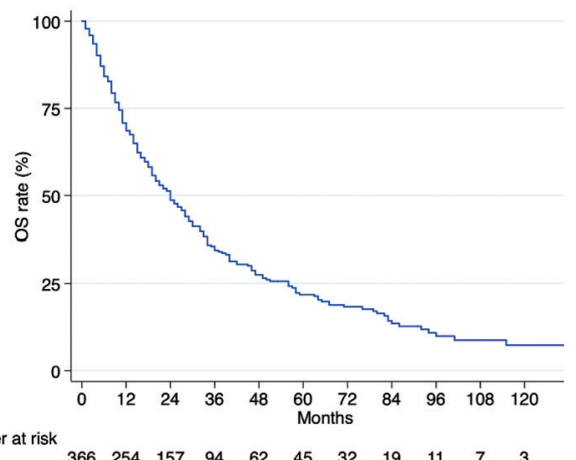

Figure S1 Disease-specific survival (DSS) and overall survival (OS) in the overall cohort (A and B) and subgroup (C and D) of elderly patients with head and neck mucosal melanomas. 